presents symptoms of difficulty, abnormality, danger, or disease on the part of the mother or of the new-born infant.

The principle of the two clauses is the same, but while that of the Committee provides for the insertion of the requirement with some details expressly in the Bill, that of the Council entrusts the matter to the Midwives Board to be provided for in their regulations, which are to be subject to the approval of the General Medical Council.

The difficulty of inserting any clause involving money payment in private Bills is probably the reason of the noninsertion of such a clause. But I think the omission is to be regretted. I recognise the effort of the promoters to comply with the general views of the General Medical Council and cannot doubt that they do not differ seriously from the Council in wishing to subordinate all midwives' work in cases of "difficulty or abnormality" to the supervision and control of medical practitioners-a sine qua non, in my judgment, of all legislation of this sort.

I am, Sirs, your obedient servant,

Highbury-place, Jan. 25th, $1899 . \quad$ JAMES GREY GLOVER.

\section{"OLD AGE AND REJUVENESCENCE."}

\section{To the Editors of THE LANCE?.}

SIRs,--In considering whether it is possible to iacrease the acial span of life-i.e., the inborn tendency to longevitywe must not forget that it is very doubtful whether characters impressed upon the individual by the environment $c=$ acquired characters $)$ are inherited, and whether therefore the acts of the parent before the conception of the child greatly influence the latter's career. Be this as it may, it seems certain that evolution proceeds essentially by "selection," from which it follows that the most effective way of producing a long-lived race is by allowing only those to marry who belong to long-lived families. In this way the span of human life might be prolonged almost indefinitely. In another place $I$ have given reasons for $m y$ belief that the tendency of every living thing is towards immortality, and that senility is brought about by means specially evolved for the purpose, because it is of advantage to a species that nits members should not live beyond a certain term, this term differing for different species, so that the processes which make for senility come into operation at different periods for different races. While therefore I hold that the most effective way of evolving a long-lived race of men is by artificial selection, I believe the best way to prolong the life of any given individual, apart from ordinary hygienic means, is to be sought for in the study of those mechanisms by which senility is normally and physiologically induced.

What these mechanisms are cannot at present be stated very definitely. I believe, however, it will be found that changes in the composition of the blood, whether by modification in internal secretions or what not, play an important part in determining senility, and that Brown-Séquard's attempts at rejuvenescing the old were not altogether chimerical. It is certain, again, that the cardio-vascular system takes a large share in inducing senility; the degree of -gystemic arteriolar resistance helps to set the vital pace, an abnormally high resistance causing premature senility by prematurely wearing out the heart and arteries, and in this way influencing the entire bodily nutrition. If therefore we wish to keep a person young we should keep his bloodpressure low, and I believe that we can in this way stave off senility even more effectually than by the plan adopted by Dr. Althaus.

Dr. Ainslie Hollis seems to hint that delayed marriage tends to delay puberty in the offspring. I doubt whether this is the case. There is, indeed, a popular belief that the children of old men tend to develop prematurely. Such -marriages probably do, however, tend to racial longevity. If, for instance (to take an extreme case), every man delayed marriage till forty, the large number of men who die before this age from disease would be prevented from leaving children inheriting a similar tendency to early death. In this connexion I would observe that the custom of monogamy operates injuriously as regards the extension of racial life. Under this system men are for the most part prevented from begetting children after fifty, and thus those who live to be very old do not as a rule have more children than those who die at middle age. Under a system of polygamy, however, the former would leave the more numerous progeny, and thus there would be a proportionate increase in the number of children born into the world with an inherited tendency to longevity. I am, Sirs, yours faitbfully, Wimpole-street, W., Jan. 22nd, $1899 . \quad$ HaRRY CAMPIRLL.

To the Editors of THE LANCET.

SIRS, - In your leading article on my paper on the above subject in THE LANCET of Jan. 21st you state that "he appears to us to forget that obviously the vital energy of the subject, his hereditary clockwork, must still be in fair working order." Allow me to say that I have by no means forgotten this, as shown by my remark that "I have come to the conclusion that if old people receive about the sixtieth or sixtyfifth year, or indeed at any time nhen au" has begun decidedly to tell upon them, proper and faultlessly carried-out applications of electricity to the brain," then benefit may be expected. Of course, no one would think of applying electricity to an old person in articulo mortis, or in such a state of decrepitude that a response to any treatment appears to be unlikely. The treatment must be confined to elderly people who are, although decidedly failing, yet in tolerable condition and therefore likely to be benefited by it.

I am, Sirs, yours faithfully, Julius AlthaUs, M.D. Berlin.

Queen Anne-street, W., Jan. 21st, 1899

** Dr. Althaus appears to mean that benefit is only to be expected from "faultlessly carried out applications of electricity" when the recuperative powers of the patient may be expected to exert themselves unaided or under other therapeutic measures. This is an intelligible view.-ED. L.

\section{"IRRIGATION IN SUPPURATIVE OTITIS MEDIA." \\ To the Editors of THE LANCET.}

Sirs,-Mr. F. Faulder White's letter on the above subject in THE LANCET of Jan. 21st and his criticism of Dr. Goldstein's views as expressed in his article upon the Therapy of Suppurative Otitis Media ${ }^{1}$ does not seem to me to accurately place his (Dr. Goldstein's) views upon this important subject before your readers. Mr. White believes that the only efficient plan of cleansing the middle-ear cavity of its purulent contents is by means of warm irrigations, and adds, moreover, that such warm solutions are "invaluable in arousing the dormant vitality of the tissues." Dr. Goldstein, on the other hand, considers that the judicious use of the cotton-armed probe combined with inflation of the middle-ear by means of the Eustachian catheter and suction by means of a Siegle's speculum is sufficient to ensure cleansing of the part without increasing the already sodden condition of the mucosa, which, he says, is only accentuated by the addition of aqueous medication. Dr. Goldstein further remarks that he is referring only to cases of simple suppurative otitis media and not to cases of old-standing disease associated with necrosis and extensive destruction of the soft tissues of the middle-ear and possibly even involvement of the mastoid area. Mr. White, on the other hand, says that he refers to cases "of long standing in which there is no part of the middle-ear that can be said to be uninfected and yet open to the gentle force of an irrigating fluid, but there are certainly grave objections to the frequent use of the probe in the early stages of treatment."

For some considerable time past I bave been in the habit of employing in early cases of suppurative otitis mediaby which term I mean cases where the pathogenic infection is confined to the soft parts and where no bone lesion is present-the "dry method of treatment" and can claim not only good results but also more speedy recoveries than when solutions and irrigations have been made use of. It has always appeared to me that one of the main causes of the inveterate nature of certain middle-ear suppurations is due not to the virulence of the original pathogenic infection but to the engrafting of a secondary infection from without either from the use of unclean instruments, inefficient antiseptic precautions, or the generally surgically unclean habits of the patient. It has been held that the dry method of treatment should not be used in those cases where the perforation is small for fear of causing secondary retention of

1 The Laryngo:cope, December 1898. 